\title{
Effects of monocular deprivation in the nucleus rotundus of zebra finches: a Nissl and deoxyglucose study
}

\author{
K. Herrmann and H.-J. Bischof \\ Universität Bielefeld, Fakultät für Biologie, Verhaltensphysiologie, Postfach 8640, D-4800 Bielefeld 1, Federal Republic of Germany
}

Summary. We evaluated in zebra finches the effects of monocular deprivation on morphological and physiological features of the nucleus rotundus, the thalamic relay station of the tectofugal pathway. In a first series of experiments neuron size and total volume were estimated in animals deprived for 20,40 and at least 100 days and compared to values obtained from normally reared birds. Monocular closure for more than 40 days causes a marked hypertrophy in cells receiving their main input from the open eye, whereas the deprived cells are normal in size. However, with only 20 days of monocular deprivation both deprived and non-deprived rotundal neurons are larger than normal. This indicates that monocular closure has a biphasic effect: firstly, an unselective hypertrophy of deprived and nondeprived neurons, and secondly, a subsequent period of shrinkage of the deprived cells to normal values, while cells driven by the open eye remain hypertrophied. The total volume of the deprived $\mathrm{n}$. rotundus turns out to be smaller in all age groups. In a second series of experiments the activity of the $\mathrm{n}$. rotundus of animals monocularly deprived from birth for 100 days was investigated with the 2deoxyglucose-method (Sokoloff et al. 1977). With binocular stimulation the activity of the deprived n. rotundus was reduced by about $40 \%$. Depriving adult animals for 100 days does not result in asymmetric labeling of the $n$. rotundus. We interpretate the 2-DG data as evidence for the existence of a sensitive period for the effects of monocular deprivation. The anatomical data suggest, however, that the effects of monocular deprivation in birds are different from those observed in mammals.

Key words: Monocular deprivation - Visual system Birds - Neuron size - 2-deoxyglucose

\section{Introduction}

The visual system of mammals is one of the best investigated models for the influence of the environment on the development of the nervous system. Since the pioneering work of Hubel and Wiesel in the early sixties ample evidence has accumulated demonstrating that abnormal experience during infancy can drastically and irreversibly alter structural and functional features of central visual pathways (for review see Blakemore 1978; Sherman and Spear 1982; Fregnac and Imbert 1984). Monocular deprivation leads to a severe loss of cells excitable from the deprived eye (Wiesel and Hubel 1963, 1965), if the closure is maintained during the so-called sensitive period. The functional effects are associated with a reduction in the size of ocular dominance columns (Hubel et al. 1977; Le Vay et al. 1980) and with differential shrinkage of cells in the lateral geniculate nucleus (Kupfer and Palmer 1964; Guillery and Stelzner 1970; Guillery 1972; Sherman and Wilson 1975; Vital-Durand et al. 1978; Casagrande and Joseph 1980; Headon et al. 1985).

Most of the physiological and anatomical changes following early unilateral lid closure have been attributed to an unbalanced binocular competition (Wiesel and Hubel 1965; Guillery and Stelzner 1970; Guillery 1972). This interpretation is supported by three findings: first, binocular deprivation causes milder electrophysiological (Wiesel and Hubel 1965) and anatomical effects (Guillery 1973; Hickey et al. 1977; Kalil 1980; but see Vital-Durand et al. 1978; Mower et al. 1985). Second, cell sizes in the monocular or artificially induced "critical" segment are less affected by monocular closure than neurons in the binocular LGN segments (Guillery and Stelzner 1970; Guillery 1972; Von Norden et al. 1974). Third, monocular deprivation in rabbits, mammals with a predominantly monocular geniculocortical pathway, 


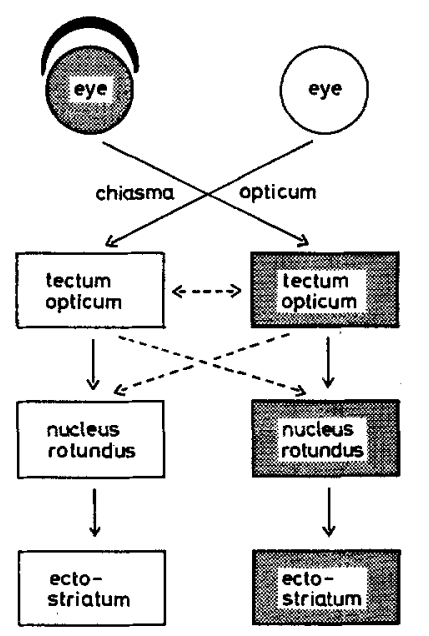

Fig. 1. Monocular deprivation in birds has major effects on the tectofugal structures contralateral to the deprived eye. $\longrightarrow$ major projections, $\rightarrow$ minor projections

produces less structural and functional changes than visual deprivation in a predominantly binocular pathway (Chow and Spear 1974).

In spite of the large body of literature on the mammalian system, relatively little is known about effects of monocular deprivation in birds. A study by Pettigrew and Konishi (1976), however, demonstrated, that the sensitivity to manipulations of early visual experience of neurons in the visual wulst (probably homologous to the visual cortex) of owls, a species with a large binocular field, resembles that of cats or monkeys. More recent studies on monocular deprivation in the visual wulst of pigeons also suggest similarities to the mammalian visual system (Bagnoli et al. 1982; Burkhalter et al. 1982).

The aim of this study was to determine, whether the nucleus rotundus, the diencephalic relay - station of the tectofugal pathway (Karten 1965; Nixdorf and Bischof 1982) of zebra finches is susceptible to early monocular deprivation. Due to the complete crossing of the retino-tectal connection, nucleus rotundus, probably homologous to the mammalian nucleus lateralis posterior thalami (Nauta and Karten 1970), receives its main input from the contralateral eye (Cowan et al. 1961). Thus, monocular deprivation in the tectofugal pathway creates a deprived hemisphere (contralateral to the deprived eye, shaded in Fig. 1) and a non-deprived hemisphere (ipsilateral to the deprived eye), although there is a minor tectotectal and a small projection form the tectum opticum to the contralateral nucleus rotundus (Benowitz and Karten 1976; Hunt and Künzle 1980) (Fig. 1). However, no binocular neurons have been reported in the tectofugal pathway so far.
We determined cell size and volume differences in birds deprived for various periods, similar to studies on the LGN morphology, and examined metabolic activity of the nucleus rotundus of monocularly deprived zebra finches, using the 2-Deoxyglucose-method.

\section{Material and methods}

\section{a. Subjects}

27 zebra finches (Taeniopygia guttata castanotis) of both sexes from the institute's stock were used for this study, 22 for the evaluation of cell size and volume, and 5 for the 14C-2-Deoxyglucose (2DG)-experiments. The birds were monocularly deprived (left or tight, as described later) on the first or second day of life until they were sacrificed and perfused for anatomical processing. Survival times were $20(n=4), 40(n=3)$ or more than a 100 days $(n=3)$. Furthermore, $20(n=4), 40(n=4)$, and at least 100 day old normally reared zebra finches $(n=4)$ were used as controls.

For the 2DG-study, 2 birds were monocularly deprived from birth to at least 100 days of age and two birds deprived as adults for 100 days. In all birds the lids were reopened under anaesthesia one day before the 2DG-experiment, so that the birds were binocularly stimulated during the exposure. In addition, one bird was monocularly deprived the day before the 2DG-study and then monocularly stimulated during the 2DG-experiment.

\section{b. Lid suture}

We used two methods for closing the eyes: for depriving adult animals we usually glued a plastic cap onto one eye, using DowCorning Adhesive. Young birds were deprived, beginning at the first or second day of life (before the natural eye opening), either by the same method mentioned above, or by spreading a liquid adhesive plaster (Nobecutan) over the closed eyelids every day, and additionally covering the eye with black eyeliner (Burkhalter and Cuenod 1979). This treatment usually prevents the development of the margin of the eyelid, causing a permanent closure of the eye. These two methods produce essentially the same results, for example bird BW was cap-deprived, whereas BK. was Nobecutan-deprived (see results for details).

\section{c. Morphological methods}

The birds were deeply anaesthetized with $0.03 \mathrm{ml}$ Nembutal, perfused via the left ventricle with $0.9 \% \mathrm{NaCl}$, followed by $10 \%$ formaline in saline. The brains were fixed in situ for several weeks and after removal from the scull they were stored in a solution of $30 \%$ sucrose in $10 \%$ formalin overnight. Frontal serial sections ( $30 \mu \mathrm{m}$ thick) were cut and every third section was mounted on gelatine-coated slides and stained with $1 \%$ cresylviolet. For the cell measurements of the nucleus rotundus the outlines of 100 neurons showing a visible nucleolus were drawn at a magnification of $800 \times$, using a drawing tube attached to a Zeiss microscope. Cells were sampled from the most medial part (in rostro-caudal as well as in mediolateral direction), excluding the dorsal part, the socalled triangularis, and the ventral part of the nucleus, which does not receive tectal efferences but input from the SP and IPS (Benowitz and Karten 1976). The cross-sectional areas were determined using a Hewlett Packard Graphics Tablett attached to a HP 85 microcomputer. From the stored data the means, medians 


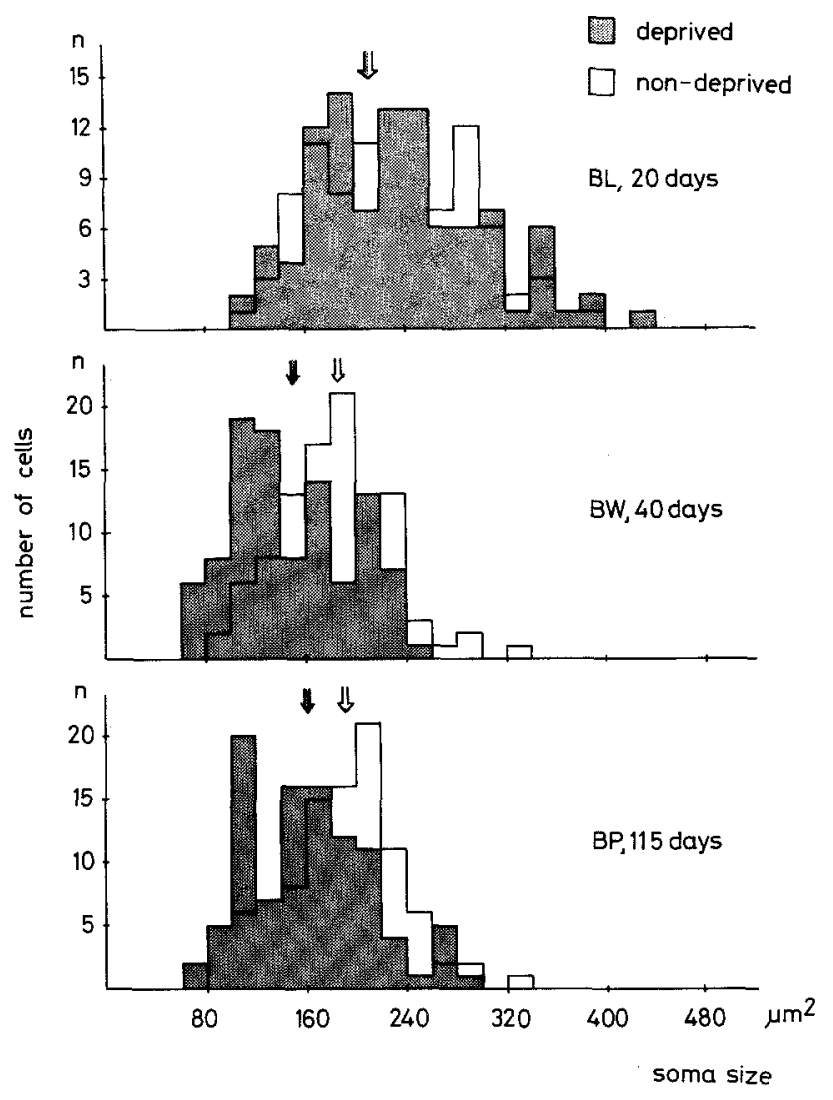

Fig. 2. Frequency histograms showing the distribution of nucleus rotundus cells of representative zebra finches deprived till sacrifice after 20 days (bird BL), 40 days (BW) and 115 days (BP). Each histogram shows the cross sectional areas of 100 cells in the deprived (shaded) and non-deprived (white) hemisphere. The open arrows mark the mean value for the cells in the non-deprived nucleus rotundus, the shaded arrows mark mean values for deprived rotundal neurons. Bin width is $40 \mu \mathrm{m}^{2}$

and standard deviations were computed and statistical comparison between cell sizes was performed by using a two-tailed $t$-test and Mann-Whitney U-test. The second test was applicated as at least some of the distributions were eventually not normally distributed. However, means and the median values were always identical (the difference never exceeded $2 \%$ ). To make the results comparable to others, we present the t-test data here, as this test is used much more frequently in comparable studies. To determine the volume of the $n$. rotundus the cross sectional area of the total rotundal surface was estimated in every third $30 \mu \mathrm{m}$ section in the same way as for cell measurements, but at a magnification of $\times 79$. The obtained areas were multiplied with $90 \mu \mathrm{m}$ and the volume slabs were added up. No adjustments were made for tissue shrinkage, as it proved to be rather constant at all ages.

\section{d. The 2DG-method}

The birds were given $0.12 \mu \mathrm{Ci}$ 14C-2-Deoxyglucose (2DG) in $0.05 \mathrm{ml} 0.9 \% \mathrm{NaCl}$ intramuscularly and allowed to view the laboratory scene for $60 \mathrm{~min}$. Then the birds were decapitated, the brains were quickly removed and rapidly frozen at $-60^{\circ} \mathrm{C}$ directly on the microtome head. On the following day the brains were cut horizontally at $30 \mu \mathrm{m}$ in a cryostat at $-17^{\circ} \mathrm{C}$. The sections were dried on a hot plate at $60^{\circ} \mathrm{C}$, and exposed for 4 weeks using a Kodak X-ray film. The autoradiographs were developed in Kodak $\mathrm{X}$-ray developer. The densitometric analysis was performed using a digital image processor. It consisted of a TV camera based digitizer, whose output was connected to a PDP-Computer system. Interhemispheric differences in the rotundus activity were assessed by comparing the relative activity of the deprived with that of the non-deprived hemisphere. Relative activity was expressed as the ratio of the mean optical density of all rotundus sections over the optical density of field $\mathrm{L}$ of the same hemisphere. Due to the constant noise-level in the lab, Field $\mathrm{L}$, the telencephalic relay of the auditory pathway in birds, was uniformly labelled in all experiments.

\section{Results \\ a. Cell size}

Table 1 shows the means and standard deviations of the cross-sectional areas of nucleus rotundus cells in experimental animals (deprived and non-deprived hemisphere) and normal zebra finches at different ages. In both, normal birds and deprived animals, cell size decreases from day 20 to day 100 . This confirms the results of an earlier study (Herrmann and Bischof 1986) and will not be discussed here. After 20 days of monocular closure there is no significant difference in the mean cell size between deprived and non-deprived nucleus rotundus (231.5 vs $233.5 \mu \mathrm{m}^{2}$ ).

The frequency distribution of neuron size of brain BL in Fig. 2 shows this total overlap of deprived and non-deprived rotundal cells. Following 40 days of monocular deprivation, the differences between deprived and undeprived cells varied between $7.7 \%$ and $18.9 \%$, with a mean of $14.9 \%$. Neurons innervated by the closed eye were significantly smaller than cells in the non-deprived nucleus rotundus (176.1 vs $\left.205.8 \mu \mathrm{m}^{2}\right)$. A typical example of rotundal soma size distribution after 40 days of monocular closure is presented in Fig. 2 (brain BW). Prolonging the deprivation duration over 100 days or more does not cause further changes: neurons driven by the deprived eye are $15.5 \%$ smaller than their contralateral counterparts $\left(162.8 \mathrm{vs} 192.6 \mu \mathrm{m}^{2}\right)$. See brain BP in Fig. 2 for example.

A comparison between rotundal cell sizes of 20 day old experimental birds with those of normally reared zebra finches indicates that cells in the latter are about $11 \%$ smaller than cells in both the deprived and the non-deprived nucleus of the experimental animals (Fig. 3, Table 1: 208.8 vs $231.5 / 233.5 \mu^{2}$ ). With 40 days of monocular closure, cells in the deprived nucleus rotundus are only little affected, as the mean cell size is only $4.9 \%$ larger in normal birds 
Table 1. Cell size

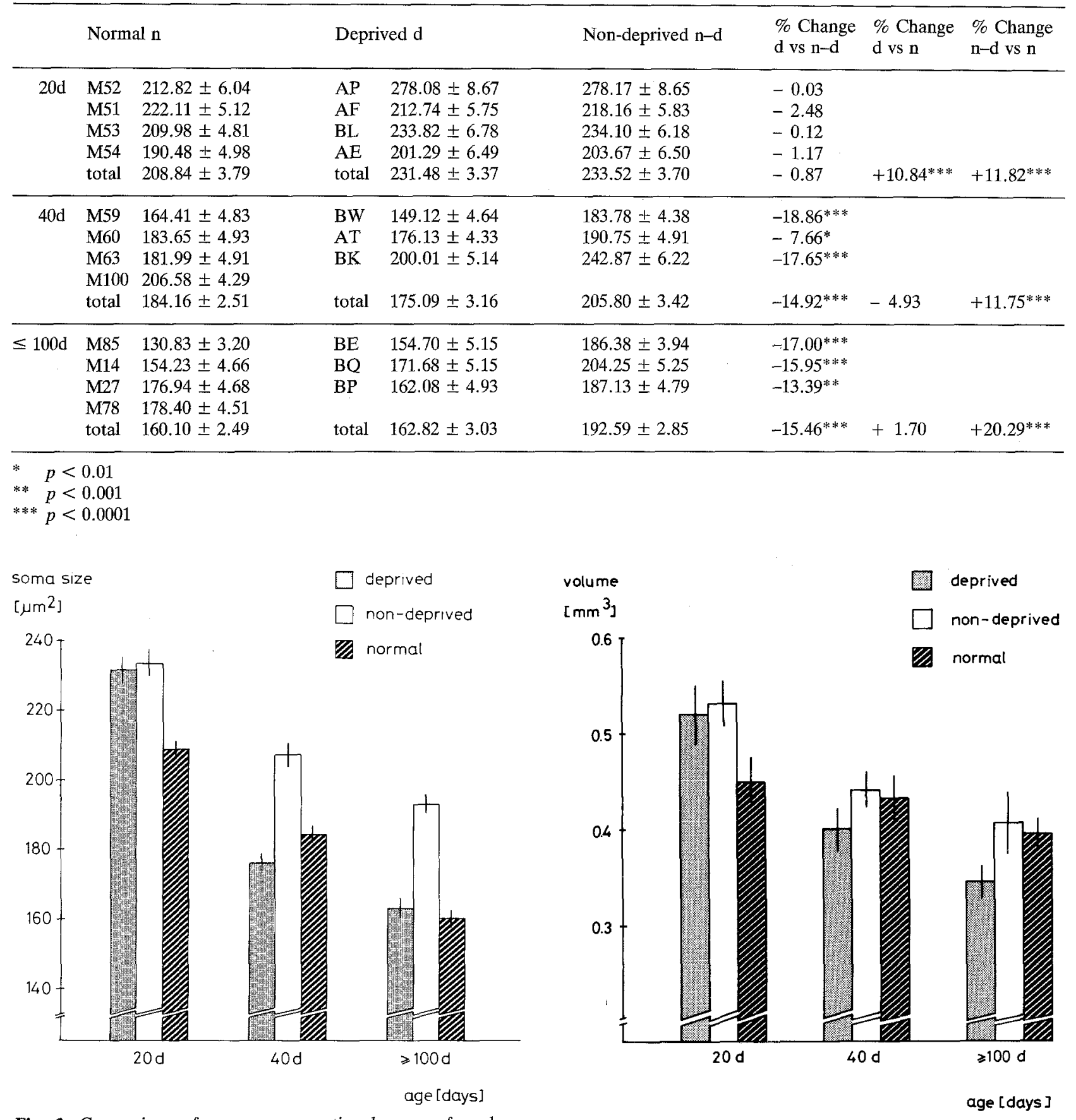

Fig. 3. Comparison of mean cross sectional areas of nucleus rotundus cells of normal and visually deprived birds (deprived and non-deprived) of different ages. The number of cells in each column is $\mathrm{n}=400$, except for 40 and 100 day old deprived birds: $\mathbf{n}=300$. Each bar represents the standard error of the mean obtained from the pooled data

than in the deprived rotundus (184.2 vs $\left.175.1 \mu \mathrm{m}^{2}\right)$, and this difference is only weakly significant $(p<0.02, \mathrm{t}=2.11, \mathrm{df}=792)$. In normal adult birds cell sizes are exactly the same as in the deprived

Fig. 4. Volume of deprived and non-deprived nucleus rotundus following different times of monocular closure in comparison to volume values of normally reared birds

rotundus of birds deprived for 100 days (160.1 vs $162.8 \mu \mathrm{m}^{2}$ ). The undeprived cells, however, are markedly hypertrophied: After 40 days of deprivation they are $11.8 \%$ (205.8 vs $175.1 \mu \mathrm{m}^{2}$ ), and after more than 100 days of deprivation they are $20.3 \%$ (192.6 vs $160.1 \mu^{2}$ ) larger than in normal animals. 

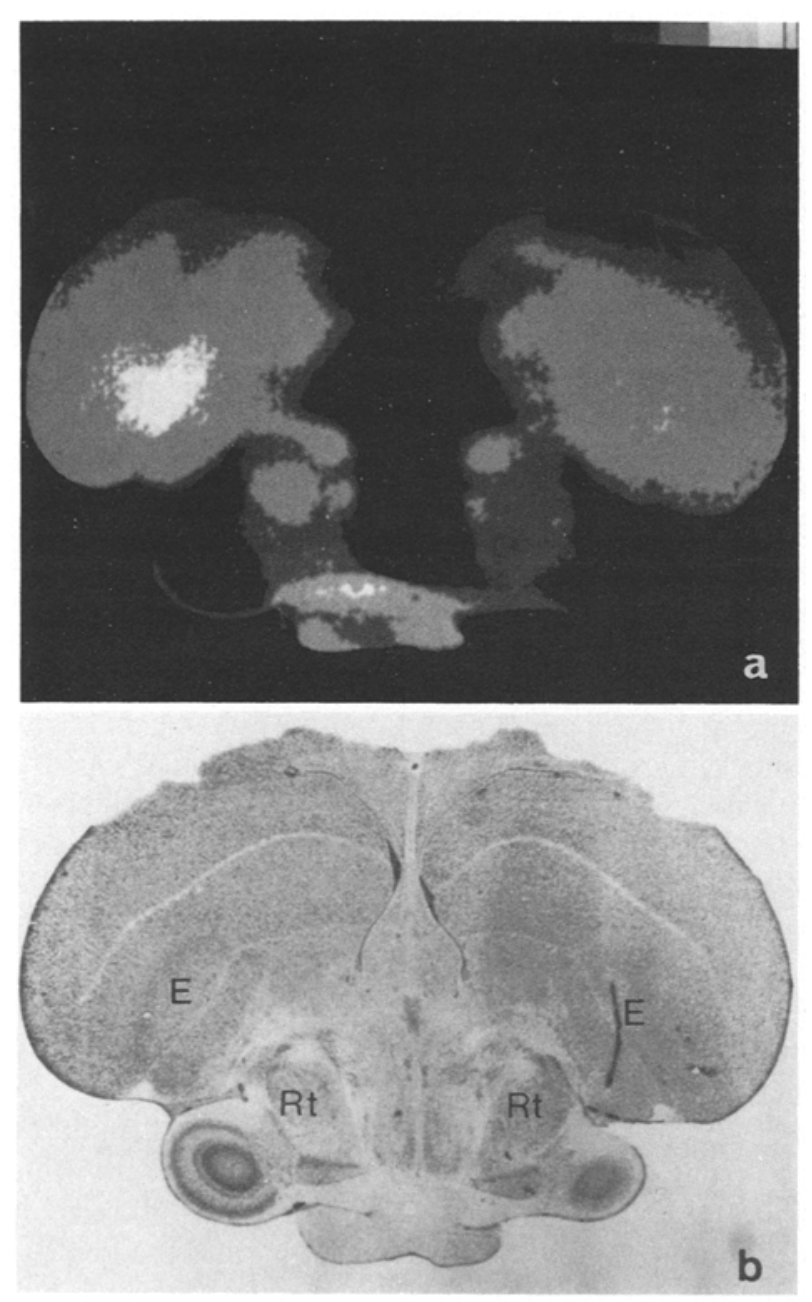

Fig. 5. a Computer generated densitometric plot of an autoradiograph (divided into 4 relative density classes) of bird $\mathrm{G} 4$, deprived from birth to day 100 . The deprived Rt (right hemisphere) shows a weaker DG-labelling. b Corresponding Nissl-section. $\mathrm{Rt}=$ n. rotundus, $\mathrm{E}=$ ectostriatum

\section{b. Volume}

The volume of nucleus rotundus undergoes the same changes with monocular deprivation as the cell size. The difference of $2.75 \%$ between deprived and nondeprived rotundus volume following 20 days of monocular closure is milder $\left(0.520 \mathrm{vs} 0.532 \mathrm{~mm}^{3}\right)$ than that observed after $40(8.5 \%, 0.401$ vs $0.439 \mathrm{~mm}^{3}$ ) or 100 days of monocular deprivation $\left(13.7 \%, 0.351\right.$ vs $\left.0.406 \mathrm{~mm}^{3}\right)$. The difference between deprived and non-deprived rotundus volume of 40 and 100 day old birds is significant at the $0.02 \%$ level (Wilcoxon signed rank-test for matched pairs). The volumes of normal rotundus is $0.450 \mathrm{~mm}^{3}$ for 20 day old birds, $0.443 \mathrm{~mm}^{3}$ for 40 day old zebra finches, and $0.396 \mathrm{~mm}^{3}$ for adult birds (at least 100 days).

\section{c. 2-deoxyglucose}

Monocular deprivation for the first 100 days of life leads to decreased glucose consumption in the nucleus rotundus contralateral to the deprived eye. In brain $\mathrm{G} 12$ the difference of relative optical density between deprived and undeprived hemisphere was $47 \%, \mathrm{G} 4$ revealed a weaker asymmetry of about $34 \%$. In both cases the difference between the optical density of left and right (or deprived and nondeprived) nucleus rotundus is highly significant $(0.001, t$-test $)$. Thus, the optical density of the nucleus rotundus driven by the deprived eye is decreased by about $40 \%$ (Fig. 5).

In contrast, in birds deprived as adults (G17 and G32) labelling of the deprived and undeprived nucleus rotundus is similar. The slightly higher labelling of the deprived nucleus is not significant.

In a normally reared bird (G27) that was stimulated monocularly the optical density was $61 \%$ lower on the side contralateral to the covered eye.

\section{Discussion}

The observed changes in rotundal cell size following monocular closure can be described in two ways: either by comparing deprived cells with those of the non-deprived nucleus rotundus of the same animal or by comparing the cell sizes of the experimental brain structures with those of normally reared birds (Headon et al. 1985). Using cells in the corresponding non-deprived nucleus rotundus of the same animal as a control, our results show that after 40 or 100 days of monocular deprivation neurons in the deprived nucleus rotundus are $15 \%$ smaller than those in the non-deprived hemisphere. Analysing our data this way, our results are in close agreement with findings in the visual system of mammalian species with large binocular fields (Guillery and Stelzner 1970; Sherman and Wilson 1975; Hickey et al. 1977; Vital-Durand et al. 1978; Casagrande and Joseph 1980; Tigges et al. 1984), although the size differences expressed as percentage between deprived and undeprived cells in cats, monkeys, squirrels and dogs are about twice as high as those observed in zebra finches. After a shorter deprivation time of 20 days, however, there are no differences in cell size between the two hemispheres. Therefore, one would conclude, that 20 days of monocular deprivation is too short a time to produce any cell size changes. This observation of delayed response to monocular closure is consistent with findings of Chow and Spear (1974) in the rabbit visual system, who also failed to find cell size changes after short-term lid suture in this species with small binocular visual field. The 
time necessary to produce LGN neuron size changes in this species is several months and hence much longer than in zebra finches. Moreover, the deprivation effects in rabbits are much weaker than in other species including zebra finches (differences between 4.6 and $9.8 \%$ ).

Some unexpected points emerged when the deprived animals were compared to normally reared birds. As Fig. 2 shows, there is a marked hypertrophy of both deprived and non-deprived rotundal cells following 20 days of monocular deprivation. Up to now we have no conclusive explanation for this finding, which to our knowledge has not been reported in the mammalian visual system following monocular closure.

One interpretation might be that the transient uncrossed retinofugal projection is maintained or strengthened as it has been demonstrated after enucleation in chicks (O'Leary and Cowan 1980). Unfortunately, the existence and time-course of such a projection is only established for precocial, not for altrical birds like the zebra finch. It remains to be determined whether such persistence could also account for changes in the non-deprived hemisphere. Another interpretation might be that the tecto-tectal and/or the contralateral tecto-rotundal projection, mentioned above as a minor pathway, gains functional importance in the deprived birds. We have evidence from electrophysiological data (Engelage and Bischof in prep) for this second interpretation. Longer deprivation causes a hypertrophy in the cells receiving their main input from the open eye and has no effect on the deprived cells. However, a comparison of cell sizes of the deprived nucleus rotundus of 40 day old birds with neuron size values of normal zebra finches demonstrates a $4.6 \%$ shrinkage of the deprived neurons. With regard to the small number of samples we neglect this difference, which anyhow is not significant at the $99 \%$ level. Thus it appears, that the difference in pericaryal size between the deprived and the non-deprived nucleus rotundus pertains almost entirely to a hypertrophy of neurons receiving input from the open eye. Unfortunately, only little information on interindividual comparison is available. Hickey et al. (1977) obtained the first direct evidence of a hypertrophy in the deprived LGN laminae by comparing neuron sizes from normal cats with those from monocular deprived animals (but see Hoffman and Holländer 1978 and Kalil 1980 in the same species). A recent detailed study of Headon et al. (1985) on morphological changes in rhesus monkeys following monocular deprivation confirms these results. These authors also found that early deprivation initially causes growth of cells in the undeprived parvocellular laminae rather than failure of growth or shrinkage of cells in the deprived laminae. Following longer periods of deprivation in the primate, measurements of LGN neurons reveal shrinkage affecting both deprived and undeprived parvocellular cells (Headon et al. 1985).

In conclusion, then, in zebra finches the permanent hypertrophy of cells in the non-deprived nucleus rotundus and the absence of shrinkage in the deprived nucleus contrasts sharply with the effects of monocular deprivation in mammals. Considering the time-course, monocular deprivation in zebra-finches seems to have a biphasic effect: first, an unselective hypertrophy of deprived and undeprived neurons, and secondly a subsequent shrinkage of the deprived cells to normal values, while neurons driven by the open eye stay hypertrophied.

As mentioned above, there is now extensive support for the existence of competitive mechanisms underlying cell size changes after monocular closure (for review see Sherman and Spear 1982), as neurons in the monocular and "critical" part of the LGN are less affected than somata in the binocular LGN laminae (Guillery and Stelzner 1970; Garey et al. 1973; Sherman and Wilson 1975; Hickey et al. 1977; Casagrande and Joseph 1980). According to a hypothesis put forward by Guillery (1972, Guillery and Stelzner 1972) the soma size of a neuron is a reflection of its axonal arborization and the number of synapses (Tieman 1984). In line with this hypothesis is the close correlation between the size of ocular dominance columns in area 17 and the geniculate cell size after monocular deprivation, which has been shown in a variety of studies (Hubel et al. 1977; Le Vay et al. 1980; Swindale et al. 1981; Tigges et al. 1984).

Unfortunately, this evidence has only limited value for the interpretation of our results. Thus, we do not know whether binocular competition is at all relevant. Despite the discovery of the small contralateral tecto-rotundal projection (Benowitz and Karten 1976), there are yet no hints for binocular mechanisms in this thalamic nucleus.

The interpretation of the 2DG results poses fewer problems. The decreased activity of the non-stimulated rotundus of the monocularly stimulated normal bird G27 confirms earlier results in the pigeon (Streit et al. 1977) and the falcon visual system (Bagnoli and Francesconi 1983). This indicates that the 2DG method is well suitable for the measurement of activity in the visual system of birds.

The decreased optical density of the early deprived nucleus rotundus is thus likely to reflect decreased neuronal activity and thus might reflect a failure to adaequately respond to visual stimulation. This result is in accordance with a $2 D G$ study of 
area 17 of squirrel monkeys ('Tigges et al. 1984) after monocular deprivation. The decreased optical density of the deprived nucleus rotundus in zebra finches, however, is in contrast to deprivation studies in pigeons: Burkhalter et al. (1983) reported no asymmetries in 2DG activity in the tectofugal pathway after early monocular deprivation. As the interhemispheric difference in DG-consumption in the pigeon study was not expressed quantitatively, the differences might have been overlooked.

Since in birds deprived as adults the 2DG distribution shows no side difference, a sensitive period for the effects of monocular deprivation has to be assumed, as has been established for the mammalian visual system (e.g. Blakemore and Van Sluyters 1974). Results on two biochemical systems, the enzymes GAD and ChAT in the pigeon (Bagnoli et al. 1982), and the physiological findings of Pettigrew and Konishi (1976) on the owl's visual wulst also suggest the existence of an early sensitive period.

There is every reason to believe, that this critical period also exists for cell size changes. Measurements of rotundal cells of birds, whose eyes were not properly deprived because they lost their eyecaps for 1 or 2 days during the first 20 days of life (and were therefore omitted from this study), revealed no asymmetry in neuron size. We are currently investigating the time course of the sensitive period for the effects of monocular deprivation.

Acknowledgements. Our thanks are due to Prof. W. Singer for providing us with the computer facilities for the densitometric analysis of the deoxyglucose autoradiograms and for helpful comments on an earlier draft of the paper. Mrs. E. Geißler provided excellent technical assistence. Robert Church improved the English text. Supported by grants from the "Minister für Wissenschaft und Forschung des Landes Nordrhein-Westfalen" and the "Deutsche Forschungsgemeinschaft" (Bi 245/3).

\section{References}

Bagnoli P, Burkhalter A, Vischer A, Henke H, Cuenod M (1982) Effects of early monocular deprivation in choline acetyltransferase and glutamic acid decarboxylase in the pigeon visual wulst. Brain Res 247: 289-302

Bagnoli P, Francesconi W (1983) Mapping of functional activity in the falcon visual system with 14C-2-deoxyglucose. Exp Brain Res 53: 217-222

Benowitz L, Karten HJ (1976) Organization of the tectofugal pathway in the pigeon: a retrograde transport study. J Comp Neurol 167: 503-520

Blakemore C (1978) Maturation and modification in the developing visual system. In: Heid R, Leibowitz HW, Teuber HL (eds). Perception. Handbook of sensory physiology, Vol VIII. Springer, Heidelberg, pp 377-426

Blakemore C, Van Sluyters RC (1974) Reversal of the physiologi- cal effects of monocular deprivation in kittens: further evidence for a sensitive period. J Physiol 237: 195-216

Burkhalter A, Cuenod M (1979) Effects of early visual deprivation on pattern discrimination learning and intraocular transfer in the pigeon (Columba livia). In: Russell JS, van Hof MW, Berlucci G (eds) Structure and function of cerebral hemispheres. The Mac Millan Press, London, pp 98-110

Burkhaiter A, Streit P, Bagnoli P, Vischer A, Henke H, Cuenod $M$ (1982) Deprivation induced functional modifications in the pigeon visual system. In: Ajmone Marsan C, Mathies H (eds) Neuronal plasticity and memory formation. Raven Press, New York, pp 477-485

Casagrande VA, Joseph R (1980) Morphological effects of monocular deprivation and recovery on the dorsal lateral geniculate nucleus in Galago. J Comp Neurol 194: 413-426

Chow KL, Spear PD (1974) Morphological and functional effects of visual deprivation on the rabbit visual system. Exp Neurol 42; 429-447

Cowan WM, Adamson L, Powell TPS (1961) An experimental study of the avian visual system. J Anat (Lond) 95: 545-563

Fregnac Y, Imbert M (1984) Development of neuronal selectivity in primary visual cortex of cat. Physiol Rev 64: 325-434

Garey LJ, Fisken RA, Powell TPS (1973) Effects of experimental deafferentation on cells in the lateral geniculate nucleus of the cat. Brain Res 52: 363-369

Guillery RW (1972) Binocular competition in the control of geniculate cell growth. J Comp Neurol 144: 117-127

Guillery RW (1973) The effect of lid surure upon the growth of cells in the dorsal lateral geniculate nucleus of kittens. J Comp Neurol 148: 417-422

Guillery RW, Stelzner DJ (1970) The differential effects of unilateral lid closure upon the monocular and binocular segments in the dorsal lateral geniculate nucleus in the cat. $\mathbf{J}$ Comp Neurol 139: 413-422

Headon MP, Sloper JJ, Hirons RW, Powell TPS (1985) Effects of monocular closure at different ages on deprived and undeprived cells in the primate lateral geniculate nucleus. Dev Brain Res 18: 57-78

Herrmann K, Bischof HJ (1986) Delayed development of song control nuclei in the zebra finch is related to behavioral development. J Comp Neurol 245: 167-175

Hickey TL, Spear PD, Kratz KE (1977) Quantitative studies of cell size in the cat's dorsal lateral geniculate nucleus following visual deprivation. J Comp Neurol 172: 265-282

Hoffman KP, Holländer H (1978) Physiological and morphological changes in cells of the lateral geniculate nucleus in monocularly-deprived and reverse-sutured cats. J Comp Neurol 177: 145-158

Hubel DH, Wiesel TN (1970) The period of susceptability to the physiological effects of unilateral eye closure in kittens. J Physiol 206: 419-436

Hubel DH, Wiesel TN, LeVay S (1977) Plasticity of ocular dominance columns in monkey striate cortex. Philos Trans $\mathrm{R}$ Soc Lond B 278: 377-409

Hunt SP, Künzle H (1976) Observations on the projections and intrinsic organization of the pigeon optic tectum: an autoraphic study based on anterograde and retrograde axonal and dendritic flow. J Comp Neurol 170: 153-172

Kalil R (1980) A quantitative study of the effects of monocular enucleation and deprivation on cell growth in the dorsal lateral geniculate nucleus of the cat. J Comp Neurol 189: 483-524

Karten HJ (1965) Projections of the optic tectum of the pigeon Columbia livia. Anat Rec 151: 369

Kupfer C, Palmer P (1964) Lateral geniculate nucleus: histological and cytochemical changes following afferent denervation and visual deprivation. Exp Neurol 9: 400-409 
Le Vay S, Wiesel TN, Hubel DH (1980) The development of ocular dominance columns in normal and visual deprived monkeys. J Comp Neurol 191: 1-51

Mower GD, Caplan CJ, Christen WG, Duffy FH (1985) Dark rearing prolongs physiological but not anatomical plyasticity of the cat visual cortex. J Comp Neurol 235: 448-466

Nauta WJH, Karten HJ (1970) A general profile of the vertebrate brain with sidelights of an ancestry of the cerebral cortex. In: Schmitt FO (ed) The neurosciences second study program. Rockefeller University Press, New York, pp 7-26

Nixdorf BE, Bischof H-J (1982) Afferent connections of the ectostriatum and visual wulst in the zebra finch (Taeniopygia guttata castanotis GOULD): an HRP-study. Brain Res 248: 9-17

O'Leary DDM, Cowan CM (1980) Observations on the effects of monocular and binocular eye removal on the development of the chick visual system. Soc Neurosci Abstr 6: 297

Pettigrew J, Konoshi M (1976) Effect of monocular deprivation on binocular neurones in the owl's visual wulst. Nature 264: 753-754

Sherman SM, Spear PD (1982) Organization of visual pathways in normal and visually deprived cats. Physiol Rev 62: 738-855

Sherman SM, Wilson JR (1975) Behavioral and morphological evidence for binocular competition in the postnatal development of the dog's visual system. J Comp Neurol 161: 163-196

Streit P, Burkhalter A, Stella M, Cuenod M (1980) Patterns of activity in the pigeon brain's visual relays as revealed by the 14C-2-deoxyglucose method. Neuroscience 5: 1053-1066

Sokoloff L, Reivich M, Kennedy C, de Rosiers MH, Patlak CS, Pettigrew KD, Sakurada O, Shinohara M (1977) The 14Cdeoxyglucose method for the measurement of local cerebral glucose utilization: theory, procedure and normal values in the conscious and anaesthetized albino rat. J Neurochem 28: 897-916

Swindale NV, Vital-Durand F, Blakemore C (1981) Recovery from monocular deprivation in the monkey. III. Reversal of anatomical effects in the visual cortex. Proc R Soc Lond B 213: $435-450$

Tieman SB (1984) Effects of monocular deprivation on the geniculocortical synapses in the cat. J Comp Neurol 222: $166-176$

Tigges M, Hendrickson AE, Tigges J (1984) Anatomical consequences of long-term monocular eyelid closure on lateral geniculate nucleus and striate cortex in squirrel monkey. J Comp Neurol 217: 1-13

Vital-Durand F, Garey LJ, Blakemore C (1978) Monocular and binocular deprivation in the monkey: morphological effects and reversability. Brain Res 158: 45-64

Von Norden GK, Crawford MLJ, Middleditch P (1976) The effect of monocular visual deprivation: disuse or binocular interaction? Brain Res 111: 277-285

Wiesel TN (1982) Postnatal development of the visual cortex and the influence of environment. Nature 299: 583-591

Wiesel TN, Hubel DH (1963) Single cell responses in striate cortex of kittens deprived of vision in one eye. J Neurophysiol 26: 1003-1017

Wiesel TN, Hubel DH (1965) Comparison of the effects of unilateral and bilateral closure on cortical unit responses in kittens. J Neurophysiol 28: 1029-1040

Wilson J, Tessin DE, Sherman SM (1983) Development of cell size in the medial interlaminar nucleus of normal and monocularly deprived kittens. Dev Brain Res 8: 53-59

Received November 28, 1985 / Accepted May 15, 1986 